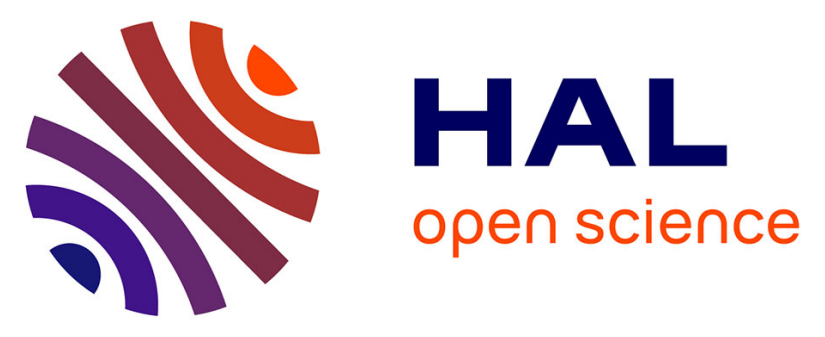

\title{
Integrated optical amplifiers and microspherical lasers based on erbium-doped oxide glasses
}

\author{
Giancarlo C. Righini, Carole Arnaud, Simone Berneschi, Marco Bettinelli, \\ Massimo Brenci, Alessandro Chiasera, Patrice Feron, Maurizio Ferrari, \\ Maurizio Montagna, Gualtiero Nunzi-Conti, et al.
}

\section{To cite this version:}

Giancarlo C. Righini, Carole Arnaud, Simone Berneschi, Marco Bettinelli, Massimo Brenci, et al.. Integrated optical amplifiers and microspherical lasers based on erbium-doped oxide glasses. 2nd International Workshop on Photonic and Electronic Materials, 2005, San Sebastian, Spain. pp.17111717, 10.1016/j.optmat.2004.11.041 . hal-00167949

\section{HAL Id: hal-00167949 \\ https://hal.science/hal-00167949}

Submitted on 8 Nov 2021

HAL is a multi-disciplinary open access archive for the deposit and dissemination of scientific research documents, whether they are published or not. The documents may come from teaching and research institutions in France or abroad, or from public or private research centers.
L'archive ouverte pluridisciplinaire HAL, est destinée au dépôt et à la diffusion de documents scientifiques de niveau recherche, publiés ou non, émanant des établissements d'enseignement et de recherche français ou étrangers, des laboratoires publics ou privés. 


\title{
Integrated optical amplifiers and microspherical lasers based on erbium-doped oxide glasses
}

\author{
G.C. Righini ${ }^{a, *}$, C. Arnaud ${ }^{b}$, S. Berneschi ${ }^{\text {a,c }}$, M. Bettinelli ${ }^{\text {d }}$, M. Brenci ${ }^{\text {a }}$, A. Chiasera ${ }^{\text {f }}$, \\ P. Feron ${ }^{\text {b }}$, M. Ferrari ${ }^{f}$, M. Montagna ${ }^{\text {e }}$, G. Nunzi Conti ${ }^{\text {a }}$, S. Pelli ${ }^{\text {a }}$, H. Portales ${ }^{\text {e }}$, \\ C. Siligardi ${ }^{g}$, A. Speghini ${ }^{d}$, L. Zampedri ${ }^{f}$ \\ a Optoelectronics \& Photonics Department, Nello Carrara Institute of Applied Physics, IFAC-CNR, Via Panciatichi 64, 50127 Firenze, Italy \\ ${ }^{\mathrm{b}}$ Laboratoire d'Optronique (CNRS-UMR 6082-FOTON), ENSSAT, 6 rue de Kerampont, 22300 Lannion, France \\ ${ }^{\mathrm{c}}$ Dipartimento di Elettronica Informatica e Sistemistica (DEIS), Bologna University, Viale Risorgimento 2, 40100 Bologna, Italy \\ ${ }^{\mathrm{d}}$ Scientific and Technological Department, Verona University, Strada le Grazie 15, 37134 Verona, Italy

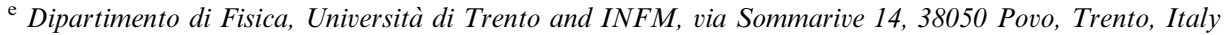 \\ ${ }^{\mathrm{f}}$ CNR-IFN, Istituto di Fotonica e Nanotecnologie, CSMFO group, via Sommarive 14, 38050 Povo, Trento, Italy \\ g Dipartimento Ingegneria dei Materiali e dell'Ambiente (DIMA), Modena and Reggio Emilia University, Via Vignolese 905,41100 Modena, Italy
}

\begin{abstract}
$\mathrm{Er}^{3+}$-doped glasses have been a subject of great interest in the recent years for their application in the areas of guided wave optical amplifiers and lasers. Oxide-glass matrices, in particular, offer the advantage of relatively simple fabrication processes-both for bulk glasses and optical fibers - and have demonstrated quite good properties in the $1.5 \mu \mathrm{m}$ wavelength band. Here we present some results we have obtained in the development of different silica-based glasses and in their application to the production of integrated optical amplifiers and microspherical lasers. As to the former application, two classes of silica glasses have been produced and investigated, namely a melted soda-lime-alumino-silicate glass and a sol-gel silica-hafnia glass. Both of them exhibit a wide emission bandwidth and seem quite promising for broadband optical amplifiers. We also demonstrated low-threshold microlasers, based on whispering gallery mode spherical resonators, fabricated in different oxide glasses.
\end{abstract}

Keywords: Silica glass; $\mathrm{Er}^{3+}$-doped glass; Optical amplifier; Microsphere; Microlaser; Integrated optics

\section{Introduction}

The possibility of confining light inside guiding films and structures has opened new perspectives in the very broad area of passive and active optical components for either telecom or sensing systems. The aim of this paper is to discuss some advances in guided-wave struc-

\footnotetext{
* Corresponding author. Tel.: +39 055 4235239; fax: +39055 4235350.

E-mail address: g.c.righini@ifac.cnr.it (G.C. Righini).
}

tures for light amplification and lasing, based on oxide glasses. In particular, reference will be made to (a) planar optical waveguides, fabricated in erbium-doped silica glasses, that appear quite promising for the development of broadband integrated optical amplifiers, and (b) dielectric spherical microresonators, where the light is guided through whispering-gallery modes (WGMs), that allowed us to demonstrate low-threshold microlasers.

For what concerns the development of $\mathrm{Er}^{3+}$-doped waveguide amplifiers (EDWAs), we have focused our 
attention on silica-based glasses in virtue of their good chemical durability and adaptability to different waveguide fabrication process. A net optical gain of $1.5 \mathrm{~dB} /$ $\mathrm{cm}$ was demonstrated in $\mathrm{Er}^{3+} / \mathrm{Yb}^{3+}$ co-doped sodalime-silicate glasses [1,2]. Their performance, however, was limited by the relatively narrow fluorescence bandwidth, the full width half maximum (FWHM) value being around $17 \mathrm{~nm}$. We have therefore searched for novel materials that could offer a larger bandwidth: as it is well known that introduction of aluminum in a silicate glass may lead to increase the emission bandwidth $[3,4]$, a first approach has been that of co-doping our soda-lime-silicate glass matrix with different quantities of aluminum oxide (up to about $20 \mathrm{~mol} \%$ ) and to investigate the effect of aluminum content on the optical properties of the glass and in particular on the emission bandwidth of the ${ }^{4} \mathrm{I}_{13 / 2} \rightarrow{ }^{4} \mathrm{I}_{15 / 2} \mathrm{Er}^{3+}$ ions transition at $1550 \mathrm{~nm}$. A second approach has concerned the use of sol-gel-derived silica-hafnia films, that represent an innovative binary glass system with valuable optical, spectroscopic and structural characteristics [5]. Here we report on the spectroscopic properties of these two glass systems, and on the characteristics of the corresponding optical waveguides.

As to the second issue, it is well known that in dielectric spheres light can be guided through high-Q whispering-gallery-modes with an unique combination of strong temporal and spatial confinement of light. Glass microspheres are of interest for a large number of applications, such as cavity quantum electrodynamics [6], nonlinear optics [7], photonics [8] and chemical or biological sensing [9]. In particular, since the studies on morphology-dependent-resonances (MDRs) and lasing effects in droplets during the 1980s [10], rare earth doped glass microsphere lasers have become the subject of many investigations and have been demonstrated as potentially compact laser sources [11-13]. Here we briefly report both on the spectroscopic characterization of an $\mathrm{Er}^{3+}$ doped microsphere in a modified-silicate glass, and on lasing action in that glass and in an $\mathrm{Er}^{3+} / \mathrm{Yb}^{3+}$ co-doped phosphate glass.

\section{Experimental}

\subsection{Sol-gel silica-hafnia films}

By using the sol-gel process, we produced and subsequently tested several films of composition $(100-x)$ $\mathrm{SiO}_{2}-x \mathrm{HfO}_{2}(x=10,20,30,40)$, with the aim of assessing the role of hafnia concentration on the structural and optical properties of these waveguides. Two different sets of films were produced, containing 0.01 and $0.3 \mathrm{~mol} \% \mathrm{Er}^{3+}$ ions, respectively. All the films were deposited on cleaned pure-silica substrates by dip-coating. After each layer's deposition, the sample was annealed in air for $50 \mathrm{~s}$ at $900{ }^{\circ} \mathrm{C}$. After a 10-dip cycle, the film was heated for $2 \mathrm{~min}$ at $900{ }^{\circ} \mathrm{C}$. Finally, the waveguides were subject to a further annealing at $900{ }^{\circ} \mathrm{C}$, whose duration was different for each waveguide; for instance, for the samples containing $0.3 \mathrm{~mol} \% \mathrm{Er}^{3+}$ the annealing time was varying from $30 \mathrm{~h}(x=10)$ down to $5 \mathrm{~min}(x=40)$. The necessary number of dips for the corresponding samples was 50 and 25. More details on the fabrication process are available in previous papers $[5,14]$.

Modal characterization was performed by the well known dark-line spectroscopy; one TE and one TM mode at $632.8 \mathrm{~nm}$ were supported by each waveguide.

Photoluminescence measurements in the region of the ${ }^{4} \mathrm{I}_{13 / 2} \rightarrow{ }^{4} \mathrm{I}_{15 / 2}$ transition and decay curves from the ${ }^{4} \mathrm{I}_{13 / 2}$ level were obtained with the experimental set-up described elsewhere [15]. All the spectroscopic measurements were, thus, made in guided-wave configuration, using prism coupling and as excitation source either the $980 \mathrm{~nm}$ line of a Ti:sapphire laser or the $514.5 \mathrm{~nm}$ line of an argon laser.

\subsection{Soda-lime-alumino-silicate glasses and ion- exchanged waveguides}

These glasses were prepared by conventional melting process and had a basic composition of the type $\mathrm{Na}_{2} \mathrm{O}-\mathrm{CaO}-\mathrm{Al}_{2} \mathrm{O}_{3}-\mathrm{SiO}_{2}$ with small percentages of $\mathrm{P}_{2} \mathrm{O}_{5}$ and $\mathrm{K}_{2} \mathrm{O}$. The batches were prepared by using reagent grade $\mathrm{SiO}_{2}, \mathrm{Na}_{2} \mathrm{CO}_{3}, \mathrm{~K}_{2} \mathrm{CO}_{3}, \mathrm{Al}_{2} \mathrm{O}_{3}, \mathrm{CaCO}_{3}$, $\left(\mathrm{NH}_{4}\right)_{3} \mathrm{PO}_{4}$, and $\mathrm{Er}_{2} \mathrm{O}_{3}$ as starting materials. Melting occurred in an electrically heated furnace within Pt crucibles, following the same heating cycle: from 20 to $1000{ }^{\circ} \mathrm{C}$ at $10^{\circ} \mathrm{C} / \mathrm{min}$, with a $24 \mathrm{~h}$ soaking time at $1000{ }^{\circ} \mathrm{C}$, from 1000 to $1550^{\circ} \mathrm{C}$ at $20^{\circ} \mathrm{C} / \mathrm{min}$ and finally $1 \mathrm{~h}$ of soaking time at the maximum temperature of $1550{ }^{\circ} \mathrm{C}$. Eventually, the melt was quenched in a graphite mould to obtain small pieces of glass having a bar form; each bar was then cut to $1 \mathrm{~mm}$ thickness and optically polished on both faces. Room temperature absorption spectra were measured in the visible region using a Kontron UVICON 941 Plus double beam spectrophotometer (spectral bandwidth of $0.5 \mathrm{~nm}$ ) and in the near infrared region with a Nicolet Magna 760 FTIR spectrometer (spectral bandwidth of $2 \mathrm{~cm}^{-1}$ ) or a double beam Perkin-Elmer spectrophotometer with a resolution of $1 \mathrm{~nm}$. The fluorescence spectra of $\mathrm{Er}^{3+}$ ions were detected using a $976 \mathrm{~nm}$ laser diode as excitation source: luminescence was dispersed using a monochromator with a resolution of $1 \mathrm{~nm}$ and detected with an InGaAs photodiode and lock-in technique. Lifetime $\tau$ of the ${ }^{4} \mathrm{I}_{13 / 2}$ level was also measured after excitation at $976 \mathrm{~nm}$.

As to the waveguide fabrication process in these glasses, our attention was focused on ion-exchange; indeed, we had designed a soda-lime-silicate glass just in 
order to take advantage of a large content of $\mathrm{Na}^{+}$ions. Thus, planar optical waveguides were produced by using the $\mathrm{Ag}^{+} \Leftrightarrow \mathrm{Na}^{+}$exchange process in a dilute $\mathrm{AgNO}_{3}$ solution $\left(\mathrm{AgNO}_{3}: \mathrm{NaNO}_{3}=0.5: 99.5 \mathrm{~mol} \%\right)$ at $325^{\circ} \mathrm{C}$. Exchange times were chosen in such a way to obtain multimode waveguides, in order to use with good accuracy the inverse WKB (IWKB) method for the determination of the refractive index profile resulting from the exchange process. Modal characterization at various wavelengths was performed by dark line spectroscopy using a semi-automatic system (COMPASSO) developed at IFAC [16]. The same device had also been used to measure the refractive indices of the bulk glasses.

\subsection{Er-doped glass microspherical resonators}

Different kinds of glasses were used to produce microspheres: three experimental modified-silica glass samples, doped with $0.2,0.5$ and $1.5 \mathrm{~mol} \%$ of erbium, respectively [17], as well as a commercial $\mathrm{Er}^{3+} / \mathrm{Yb}^{3+}$ co-doped phosphate glass (Schott IOG-2), which contains $2 \mathrm{wt} \%$ of $\mathrm{Er}_{2} \mathrm{O}_{3}$ and $3 \mathrm{wt} \%$ of $\mathrm{Yb}_{2} \mathrm{O}_{3}$. The refractive indices at $632.8 \mathrm{~nm}$ of the former three glasses were equal to $1.5604,1.5607$, and 1.5871, respectively.

Each glass was ground, and microspheres were prepared from the powders by using a microwave plasma torch. Powders were axially injected and melted when passing through the plasma flame, superficial tension forces giving them their spherical shape. Free spheres were collected a few ten centimeters down. The diameter of the spheres depends essentially on the powder size and may vary from 10 to $200 \mu \mathrm{m}$ [18]. By visual analysis with a microscope, the microspheres with diameter in the range $50-100 \mu \mathrm{m}$ were selected and then glued to the stretched tip of an optical fibre ( $\sim 20-30 \mu \mathrm{m}$ in diameter), which in turn was mounted on a submicrometer translation stage.

Photoluminescence spectroscopy in the $1.5 \mu \mathrm{m}$ region was performed using the $980.8 \mathrm{~nm}$ line of a Ti:sapphire laser as excitation source. The luminescence was dispersed by a $320 \mathrm{~mm}$ single-grating monochromator with a resolution of $2 \mathrm{~nm}$. The light was detected using a $\mathrm{Si} /$ InGaAs two-colors photodiode and standard lock-in technique. Lifetime decay curves were obtained recording the signal by a digital oscilloscope. For both the precursor bulk samples and the microspheres the standard bulk measurement configuration has been used.

A single half-fibre-taper was used to couple the pump light from a pigtailed laser diode into the WGMs of the microsphere and - at the same time - to allow us to couple the fluorescence or laser light out of the microsphere. The half-taper was obtained using a fusion splicer by heating and stretching a standard telecommunication fibre until breaking. The drawn length was typically
$850 \mu \mathrm{m}$, and the taper end was reduced down to $1.5 \mu \mathrm{m}$ in diameter.

\section{Results and discussion}

\subsection{Sol-gel silica-hafnia waveguides for EDWAs}

Table 1 summarizes some optical and spectroscopic parameters of the fabricated silica-hafnia planar waveguides, together with their compositions. In all samples, birefringence is not negligible, as indicated by the significant difference between the refractive indices measured for TE and TM polarizations. Propagation losses were also measured in various samples by using the technique based on the collection of the light scattered out of the plane of the waveguide, and an average value was $\approx 0.9 \mathrm{~dB} / \mathrm{cm}$ at $632.8 \mathrm{~nm}$.

The photoluminescence (PL) spectra relative to the ${ }^{4} \mathrm{I}_{13 / 2} \rightarrow{ }^{4} \mathrm{I}_{15 / 2}$ transition of the $\mathrm{Er}^{3+}$ ions for all the waveguides, obtained upon excitation at $514.5 \mathrm{~nm}$ and $980 \mathrm{~nm}$, exhibit a main emission peak at $1.53 \mu \mathrm{m}$ and a broad FWHM spectral width of about $50 \pm 2 \mathrm{~nm}$. Fig. 1 shows the emission spectra of the samples doped with $0.3 \mathrm{~mol} \% \mathrm{Er}^{3+}$ for excitation at $514.5 \mathrm{~nm}$; the shape and the bandwidth of these spectra, however, do not change with the excitation wavelength, indicating that site selection is negligible. The similarity of PL spectra for all waveguides seems to indicate that a small inhomogeneous broadening is present independently on $\mathrm{HfO}_{2}$ content.

The measured lifetime of the ${ }^{4} \mathrm{I}_{13 / 2}$ metastable state, also reported in Table 1, decreases with the increasing of the $\mathrm{HfO}_{2}$ molar concentration. At very low $\mathrm{Er}^{3+}$ concentration, the energy transfer processes should be very improbable. Moreover, considering that in completely densified silicate glasses the multiphonon decay does not significantly affect the ${ }^{4} \mathrm{I}_{13 / 2}$ level lifetime, we can assume that the lifetimes measured at $0.01 \mathrm{~mol} \% \mathrm{Er}^{3+}$ doping level are very close to the radiative ones. Under this hypothesis, we can estimate that a quantum efficiency between $84 \%$ and $88 \%$ is obtained in all the samples doped with $0.3 \mathrm{~mol} \%$ of erbium.

\subsection{Soda-lime-alumino-silicate glasses and ion- exchanged waveguides}

The main oxides' concentrations of the six produced soda-lime-alumino-silicate glasses are reported in Table 2 , together with the emission bandwidth $\mathrm{B}$, the measured $\tau_{\text {meas }}$ and the calculated radiative $\tau_{\text {rad }}$ lifetimes of the ${ }^{4} \mathrm{I}_{13 / 2}$ metastable state. The data in the table clearly indicate an increase of the fluorescence bandwidth with the increase of alumina content.

This is also shown in Fig. 2, where the FWHM bandwidth of both the absorption and the emission peak 
Table 1

Compositional, optical and spectroscopic parameters of the $\mathrm{Er}^{3+}$-doped $(100-x) \mathrm{SiO}_{2}-x \mathrm{HfO}_{2}$ planar waveguides

\begin{tabular}{|c|c|c|c|c|c|c|}
\hline \multirow{2}{*}{$\begin{array}{l}\text { Waveguide } \\
\text { label }\end{array}$} & \multirow{2}{*}{$\begin{array}{l}\mathrm{SiO}_{2}: \mathrm{HfO}_{2} \\
\text { molar ratio }\end{array}$} & \multirow{2}{*}{$\begin{array}{l}\text { Erbium } \\
\text { content } \\
\left(\mathrm{mol}^{\circ} \%\right)\end{array}$} & \multicolumn{2}{|c|}{$n$ at $632.8 \mathrm{~nm} \pm 0.005$} & \multirow{2}{*}{$\begin{array}{l}\text { Thickness } \\
(\mu \mathrm{m}) \pm 0.05\end{array}$} & \multirow{2}{*}{$\begin{array}{l}{ }^{4} \mathrm{I}_{13 / 2} \text { lifetime } \\
(\mathrm{ms}) \pm 0.5\end{array}$} \\
\hline & & & $\mathrm{TE}$ & $\mathrm{TM}$ & & \\
\hline SH10 & $90: 10$ & 0.3 & 1.470 & 1.468 & 2.05 & 7.1 \\
\hline SH20 & $80: 20$ & 0.3 & 1.543 & 1.537 & 1.27 & 6.5 \\
\hline SH30 & $70: 30$ & 0.3 & 1.600 & 1.588 & 1.10 & 6.0 \\
\hline SH40 & $60: 40$ & 0.3 & 1.663 & 1.646 & 0.96 & 5.8 \\
\hline SH10a & $90: 10$ & 0.01 & 1.494 & 1.494 & 1.16 & 8.5 \\
\hline $\mathrm{SH} 20 \mathrm{a}$ & $80: 20$ & 0.01 & 1.562 & 1.562 & 0.69 & 7.5 \\
\hline SH30a & $70: 30$ & 0.01 & 1.605 & 1.601 & 0.69 & 7.0 \\
\hline SH40a & $60: 40$ & 0.01 & 1.664 & 1.655 & 0.53 & 6.6 \\
\hline
\end{tabular}

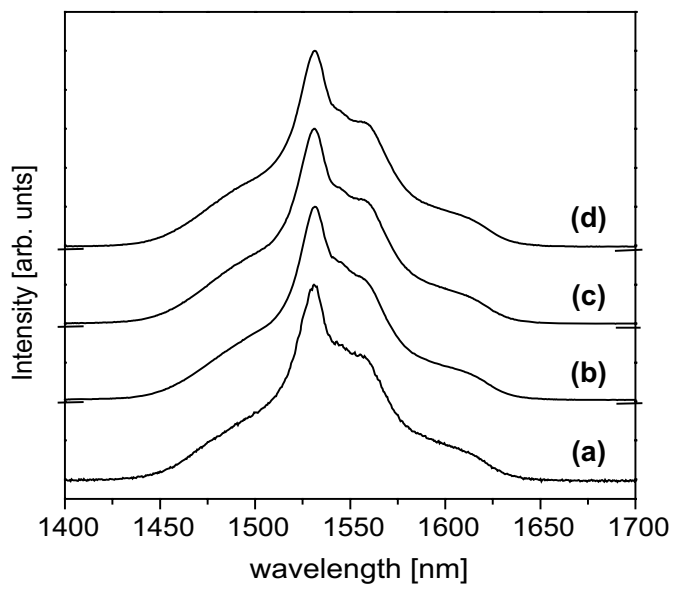

Fig. 1. Photoluminescence spectra relative to the ${ }^{4} \mathrm{I}_{13 / 2} \rightarrow{ }^{4} \mathrm{I}_{15 / 2}$ transition of the $\mathrm{Er}^{3+}$ ions for the (a) SH40, (b) SH30, (c) SH20, and (d) SH10 waveguides, obtained upon excitation at $514.5 \mathrm{~nm}$.

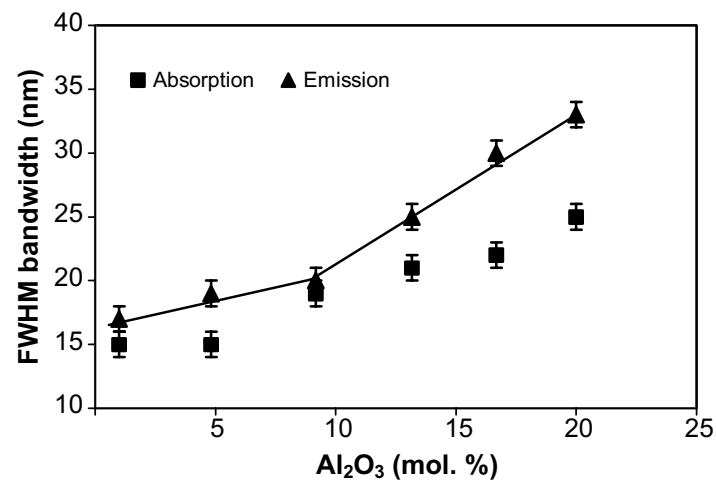

Fig. 2. Effective bandwidths (absorption and emission) as a function of $\mathrm{Al}_{2} \mathrm{O}_{3}$ concentration. The line is only traced as an help to eyes.

Table 2

Main chemical components, FWHM emission bandwidth, measured and calculated lifetimes of the ${ }^{4} \mathrm{I}_{13 / 2}$ metastable state of the six aluminosilicate glasses we had produced

\begin{tabular}{|c|c|c|c|c|c|c|c|c|}
\hline \multirow[t]{2}{*}{ Sample } & \multicolumn{5}{|c|}{ Main oxides content $(\mathrm{mol} \%)$} & \multirow{2}{*}{$\frac{B}{( \pm 1 \mathrm{~nm})}$} & \multirow{2}{*}{$\begin{array}{l}\tau_{\text {meas. }} \\
( \pm 0.2 \mathrm{~ms})\end{array}$} & \multirow{2}{*}{$\begin{array}{l}\tau_{\text {rad. }} \\
( \pm 0.2 \mathrm{~ms})\end{array}$} \\
\hline & $\mathrm{SiO}_{2}$ & $\mathrm{Na}_{2} \mathrm{O}$ & $\mathrm{Al}_{2} \mathrm{O}_{3}$ & $\mathrm{CaO}$ & $\mathrm{Er}_{2} \mathrm{O}_{3}$ & & & \\
\hline AL1 & 72.64 & 13.94 & 0.99 & 10.96 & 0.47 & 17 & 7.0 & 12.6 \\
\hline AL5 & 69.84 & 13.40 & 4.81 & 10.54 & 0.45 & 19 & 8.0 & 11.4 \\
\hline AL10 & 66.64 & 12.79 & 9.17 & 10.05 & 0.43 & 20 & 7.8 & 10.3 \\
\hline AL15 & 63.71 & 12.23 & 13.16 & 9.61 & 0.41 & 25 & 5.1 & 8.76 \\
\hline AL20 & 61.14 & 11.73 & 16.67 & 9.23 & 0.39 & 30 & 6.2 & 8.43 \\
\hline AL25 & 58.70 & 11.26 & 20 & 8.86 & 0.39 & 33 & 5.1 & 8.18 \\
\hline
\end{tabular}

around $1.5 \mu \mathrm{m}$ is plotted as a function of the alumina content. One can notice that the slope of increase of the emission bandwidth changes significantly from the region where the alumina content is lower than $9 \mathrm{~mol} \%$ to the region where the content is equal to or higher than $13 \mathrm{~mol} \%$. Correspondingly, an abrupt change in the physical (density) and optical (bulk refractive index) properties of the glass was observed as well. These facts suggest that the behaviour of this class of glasses has a drastic change when the concentration of aluminium ions becomes larger than that of sodium ions.

The measured lifetimes were compared with the radiative lifetimes calculated using Judd-Ofelt (J-O) analysis; in particular, the phenomenological intensity parameters $\Omega_{i}$ were estimated and are reported in Table 3 . The values of the $\mathbf{J}-\mathrm{O}$ parameters appear to be higher, especially for the samples at high alumina content, than 
Table 3

Judd-Ofelt intensity parameters $\left(\Omega_{i}\right)$, with their uncertainties, calculated for the six soda-alumino-silicate glasses

\begin{tabular}{llll}
\hline Glass & $\Omega_{2}\left(\mathrm{pm}^{2}\right)$ & $\Omega_{4}\left(\mathrm{pm}^{2}\right)$ & $\Omega_{6}\left(\mathrm{pm}^{2}\right)$ \\
\hline AL1 & $5.24 \pm 0.18$ & $1.11 \pm 0.25$ & $0.574 \pm 0.088$ \\
AL5 & $5.43 \pm 0.17$ & $1.15 \pm 0.24$ & $0.691 \pm 0.086$ \\
AL10 & $6.12 \pm 0.19$ & $1.38 \pm 0.26$ & $0.813 \pm 0.093$ \\
AL15 & $6.47 \pm 0.21$ & $1.60 \pm 0.28$ & $0.98 \pm 0.10$ \\
AL20 & $7.15 \pm 0.25$ & $1.95 \pm 0.34$ & $1.01 \pm 0.12$ \\
AL25 & $7.89 \pm 0.21$ & $1.83 \pm 0.28$ & $1.06 \pm 0.10$ \\
\hline
\end{tabular}

those found for other silicate glasses [19]. Moreover, a monotonic and remarkable increase of all the $\mathrm{J}-\mathrm{O}$ parameters is observed while increasing the amount of alumina in the host glass; it is in agreement with the results reported by Tanabe [4]. These values were then used to calculate the emission probabilities between the energy levels of erbium in the soda-lime-aluminosilicate host matrix, and the radiative lifetime $\tau_{\text {rad }}$ of this emission. As an example, a quantum efficiency near $75 \%$ is estimated for the AL20 sample, which has a high $\mathrm{Al}_{2} \mathrm{O}_{3}$ concentration $(16.67 \mathrm{~mol} \%$ ).

The presence of guided modes in the $\mathrm{Ag}^{+}$-exchanged glasses was checked by using an SF6 prism to couple light into the waveguides at the wavelength of $635 \mathrm{~nm}$. The effective indices of TE modes were thus measured. It appeared that, under the same ion-exchange process conditions, the number of modes supported by each waveguide was depending on the alumina content. In order to derive accurate values for the ion-exchange parameters, namely the diffusion coefficient of incoming ions $D_{\mathrm{Ag}}^{+}$and the diffusion depth $d$, in the six glasses, we found out that the best fit for the measured effective indices was an analytical function given by a linear combination between erfc and exponential functions [20]:

$$
\begin{aligned}
n(x)= & n_{\text {sub }}+\Delta n\left\{H * \operatorname{erfc}\left(\frac{x}{2 \sqrt{D t}}\right)\right. \\
& \left.+(1-H) * \exp \left(-\left(\frac{x}{2 \sqrt{2 D t}}\right)^{3}\right)\right\}
\end{aligned}
$$

where $x$ is the depth coordinate, $n_{\text {sub }}$ is the index of the glass substrate, $n_{\mathrm{s}}=n_{\text {sub }}+\Delta n$ is the surface index, $d$ is the effective depth of the waveguide, and $D=D_{\mathrm{Ag}}$. In an analogous way, $D_{\mathrm{Na}}$ indicates the effective diffusion coefficient for the $\mathrm{Na}^{+}$ions The value of $D$ is related to the diffusion time $t$ by the equation $d=(D t)^{1 / 2}$; it also depends on the molten salt solution, the glass and the temperature. It is possible to relate the fitting value $H$ to the Stewart coefficient $\alpha=1-D_{\mathrm{Ag}} / D_{\mathrm{Na}}$ [20]. Table 4 lists the number of TE modes and the values of $D_{\mathrm{Ag}}$ $\Delta n, H$ and $\alpha$ calculated for the six doped glasses after the ion-exchange. There is a marked decrease of $\Delta n$ in this class of glasses with the increase of Al content, while the diffusion coefficient $D_{\mathrm{Ag}}$ does not present a monotonic behaviour, but exhibits a maximum for the AL10 sample, that has a sodium content slightly higher than aluminium content. Fig. 3 shows the behaviour of the diffusion coefficient and the index change versus the atomic concentrations of $\mathrm{Al}$ and $\mathrm{Na}\left(\mathrm{C}_{\mathrm{Al}}\right.$ and $\mathrm{C}_{\mathrm{Na}}$, respectively). It confirms that there is a change in the diffusion process of the $\mathrm{Ag}^{+}$ions when the value of $\mathrm{C}_{\mathrm{Al}}$ approaches that of $\mathrm{C}_{\mathrm{Na}}$ ('breakpoint zone'). As a consequence, the reconstructed index profiles of the waveguides, which are shown in Fig. 4, have different shapes when $\mathrm{C}_{\mathrm{Al}}<10 \mathrm{~mol} \%$, while they are very similar for values of $\mathrm{C}_{\mathrm{Al}}>10 \mathrm{~mol} \%$.

\subsection{Er-doped glass microspherical lasers}

Spectroscopic characterization of $\mathrm{Er}^{3+}$-doped modified-silica glass microspheres indicated that both the

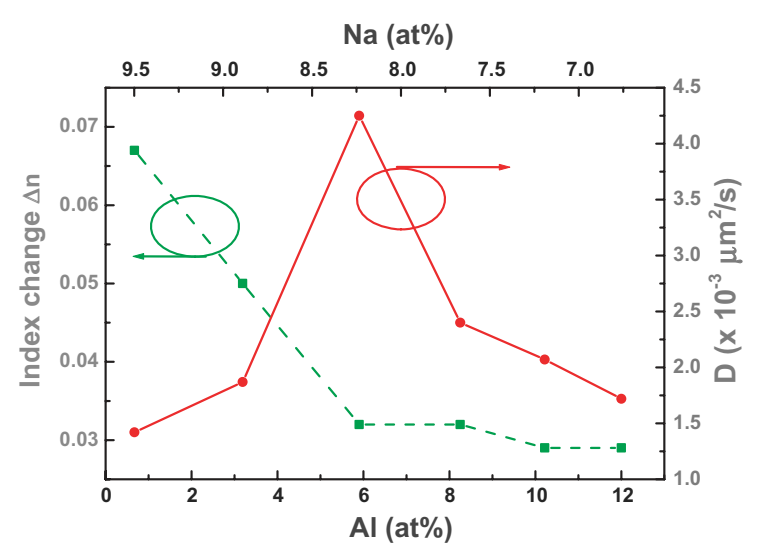

Fig. 3. Index change $\Delta n$ after ion-exchange and diffusion coefficient of $\mathrm{Ag}^{+}$ions versus the atomic concentrations of $\mathrm{Al}$ and $\mathrm{Na}$. The lines are only traced as an help to eyes.

Table 4

Ion-exchange process parameters and fitted values of $D_{\mathrm{Ag}}, \Delta n, H$ and $\alpha$ obtained using Eq. (1) as index profile for the slab waveguides fabricated in

\begin{tabular}{|c|c|c|c|c|c|c|c|}
\hline Sample & Melt salt and temperature & Exchange time (min) & Modes at $635 \mathrm{~nm}$ & $\Delta n$ & $D\left(10^{-3} \mu \mathrm{m}^{2} / \mathrm{s}\right)$ & $H$ & $\alpha$ \\
\hline AL1 & $\mathrm{AgNO}_{3}: \mathrm{NaNO}_{3}(0.5: 99.5 \mathrm{~mol} \%) 325^{\circ} \mathrm{C}$ & 90 & 11 & 0.067 & 1.42 & 0.25 & 0.94 \\
\hline AL5 & & & 11 & 0.050 & 1.87 & 0.24 & 0.93 \\
\hline AL10 & & & 13 & 0.032 & 4.25 & 0.36 & 0.89 \\
\hline AL15 & & & 10 & 0.034 & 2.57 & 0.50 & 0.83 \\
\hline AL20 & & & 8 & 0.029 & 2.07 & 0.53 & 0.81 \\
\hline AL25 & & & 7 & 0.029 & 1.72 & 0.58 & 0.78 \\
\hline
\end{tabular}
six glasses 


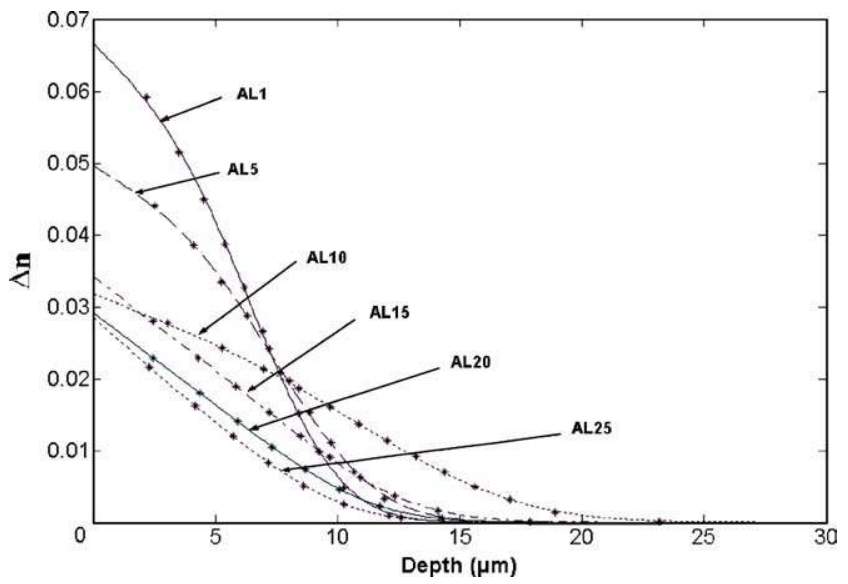

Fig. 4. Refractive index profiles of the waveguides produced by ionexchange in the six aluminosilicate glasses. The profiles were numerically reconstructed by using the function given in Eq. (1).

luminescence spectrum and the lifetime changed when passing from the bulk glass to the microsphere [21]. In fact, the emission bandwidth is larger for microspheres than for the precursor glass, demonstrating that the site-to-site inhomogeneities are effective in the microspheres. This is probably due to the fabrication process, but, due the small number of samples, so far it has been impossible to determine the specific reason of the induced inhomogeneity. Lifetimes measurements gave further information about the site-to-site inhomogeneities; the decay curves of the erbium in various microspheres all showed a faster relaxation than in the corresponding bulk glasses, indicating that energy transfer mechanism among active ions was not negligible. This behaviour is evident in Fig. 5, which compares the measured lifetimes of the bulk and microsphere glass doped with $0.5 \mathrm{~mol} \%$ of erbium oxide.

Single line laser action upon pumping at $1480 \mathrm{~nm}$ was obtained by using a $0.5 \mathrm{~mol} \%$ Er-doped microsphere of about $80 \mu \mathrm{m}$ in diameter. The laser spectrum with emis-

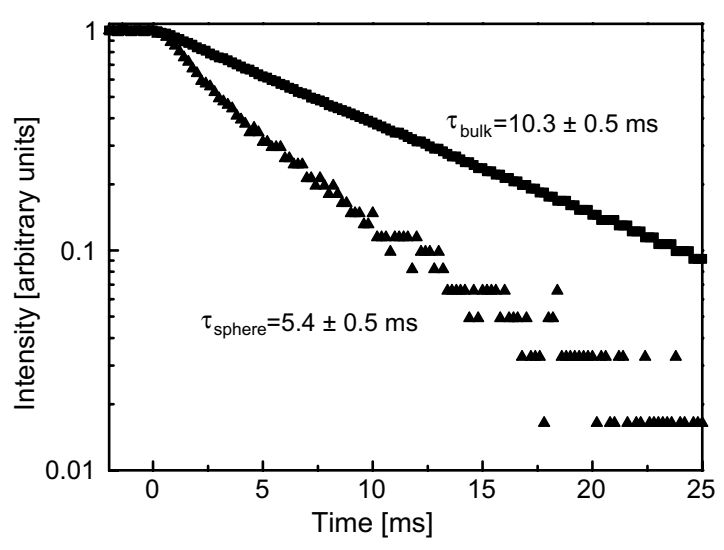

Fig. 5. Luminescence decay curve of the ${ }^{4} \mathrm{I}_{13 / 2}$ level of $\mathrm{Er}^{3+}$ ion in the bulk sample (squares) and in the microsphere (triangles) for the same modified silicate glass $(0.5 \mathrm{~mol} \%$ of erbium oxide).

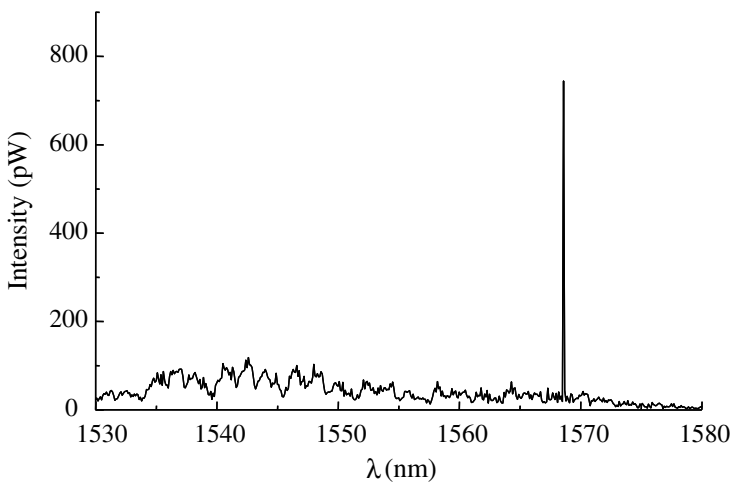

Fig. 6. Lasing spectrum of a microsphere of diameter $80 \mu \mathrm{m}$ in the modified silicate glass.

sion at $1568.5 \mu \mathrm{m}$ is shown in Fig. 6. The pump threshold was $15 \mathrm{~mW}$ (measured at the input of the tapered fiber).

As to the phosphate IOG-2 microspheres, lasing action was obtained quite easily for any sphere diameter on the range $50-100 \mu \mathrm{m}$, as reported in a previous paper [13].

\section{Conclusions}

The results we have obtained so far indicate that there are several classes of rare-earth-doped oxide glasses that are worth being investigated in greater detail with the aim of producing high-performance broadband integrated optical amplifiers. One of these glasses is represented by $\mathrm{SiO}_{2}-\mathrm{HfO}_{2}$ binary systems, where $\mathrm{Er}^{3+}$-doped sol-gel planar waveguides have shown high quantum efficiency and $\approx 50 \mathrm{~nm}$ FWHM bandwidth around $1.53 \mu \mathrm{m}$. Work is now in progress for the fabrication of channel waveguides and their characterization.

A second class is constituted by soda-lime-aluminosilicate glasses, that combine the very good chemical durability of silicates with the better spectroscopic properties induced by the presence of a relatively high percentage of aluminium. An increase up to $60 \%$ of the effective fluorescence bandwidth was observed varying alumina content from $1 \%$ to $20 \%$ molar, and an high value of quantum efficiency was calculated for these glasses. $\mathrm{Ag}^{+} \Leftrightarrow \mathrm{Na}^{+}$ion-exchanged waveguides with good characteristics were also successfully produced. Both spectroscopic and ion-exchange results have shown that there is a significant change in the behaviour of the glass when the aluminum atomic concentration is of the same order as that of sodium: these aspects are now being investigated in greater detail. Moreover, integrated optical amplifiers in these glasses are being produced and tested.

Microspherical WGM resonators were produced in other $\mathrm{Er}^{3+}$-doped oxide glasses (a modified silicate and a phosphate), with the aim of producing low-threshold 
microlasers. Preliminary studies have shown that the transformation of a glass into a microsphere could actually change the environment of erbium ions, and therefore its spectroscopic properties. This issue is being further investigated. Lasing action was obtained in both the investigated glasses.

\section{Acknowledgements}

This work was partially supported by MIUR, Italy, through the FIRB project 'Sistemi Miniaturizzati per Elettronica e Fotonica' (RBNE012N3X-005), and by the bilateral collaboration program between CNRS, France and CNR, Italy (FOTON-IFAC). The authors are grateful to B. Gaillard-Allemand and V. Benoit (Cristallerie de Baccarat, France) for providing the samples of the modified silicate glass and to Mr. Roberto Calzolai and Mr. Franco Cosi (IFAC-CNR) for their technical assistance.

\section{References}

[1] G.C. Righini, M. Brenci, M.A. Forastiere, S. Pelli, G. Ricci, G. Nunzi Conti, N. Peyghambarian, M. Ferrari, M. Montagna, Philos. Mag. B 82 (2002) 721.

[2] S. Pelli, M. Bettinelli, M. Brenci, R. Calzolai, A. Chiasera, M Ferrari, G. Nunzi Conti, A. Speghini, L. Zampedri, J. Zheng, G.C. Righini, Erbium doped silicate glasses for integrated optical amplifiers and lasers, J. Non-Cryst. Solid 345-346 (2004) 372.

[3] G.N. van den Hoven, E. Snoeks, A. Polmann, J.W.M. van Uffelen, Y.S. Oei, M.K. Smit, Appl. Phys. Lett. 62 (1993) 3065.

[4] S. Tanabe, J. Non-Cryst. Solids 259 (1999) 1.

[5] R.R. Goncalves, G. Carturan, M. Ferrari, L. Zampedri, M. Montagna, S. Pelli, G.C. Righini, S.J.L. Ribeiro, Y. Messaddeq, Opt. Mater. 25 (2004) 131.

[6] L. Collot, V. Lefèvre-Seguin, M. Brune, J.M. Raimond, S. Haroche, Europhys. Lett. 23 (1993) 327.

[7] R.K. Chang, A.J. Campillo, Optical Processes in Microcavities, World Scientific, Singapore, 1996
[8] B.E. Little, J.P. Laine, D.R. Lim, H.A. Haus, L.C. Kimerling, S.T. Chu, Opt. Lett. 25 (2000) 73.

[9] F. Vollmer, D. Braun, A. Libchaber, M. Khoshsima, I. Teraoka, S. Arnold, Appl. Phys. Lett. 80 (2002) 4057.

[10] P.W. Barber, R.K. Chang, Optical Effects Associated with Small Particles, World Scientific, Singapore, 1988.

[11] V.S. Sandoghdar, F. Treussart, J. Hare, V. Lefèvre-Seguin, J.M. Raimond, S. Haroche, Phys. Rev. A. 54 (1996) 1777.

[12] F. Lissillour, P. Féron, N. Dubreuil, P. Dupriez, M. Poulain, G. Stéphan, Electr. Lett. 36 (2000) 1382.

[13] C. Arnaud, M. Boustimi, P. Féron, G. Nunzi-Conti, G.C. Righini, Proc. SPIE 5333 (2004) 140.

[14] A. Chiasera, M. Ferrari, L. Zampedri, M. Mattarelli, M. Montagna, H. Portales, C. Tosello, S. Dirè, S. Pelli, G.C. Righini, Proc. SPIE 5451 (2004) 574.

[15] R.R. Gonçalves, G. Carturan, L. Zampedri, M. Ferrari, C. Armellini, A. Chiasera, M. Mattarelli, E. Moser, M. Montagna, G.C. Righini, S. Pelli, G. Nunzi Conti, S.J.L. Ribeiro, Y. Messaddeq, A. Minotti, V. Foglietti, H. Portales, Proc. SPIE 4990 (2003) 111.

[16] G.C. Righini, S. Pelli, M.A. Forastiere, M. Brenci, C. Bacci, in: G.C. Righini e, M.A. Forastiere (Eds.), 40 Anni Di Laser, Quaderni Di Ottica E Fotonica, Vol. 7, Centro Editoriale Toscano, Firenze, 2001, p. 71

[17] These modified silicate glasses have been developed by Cristallerie de Baccarat, France, and their exact composition has not been disclosed.

[18] P. Féron, in: Micro-optoelectronics: Materials, Devices and Integration, in: M. Ferrari, L. Pavesi, G.C. Righini (Eds.), Quaderni Di Ottica E Fotonica, Vol. 8, Centro Editoriale Toscano, Firenze, 2002, p. 117.

[19] C. Görller-Walrand, K. Binnemans, in: K.A. Gschneider Jr., L. Eyring (Eds.), Handbook on the Physics and the Chemistry of Rare Earths, Vol. 25, Elsevier, Amsterdam, 1998, p. 101.

[20] S. Sebastiani, S. Berneschi, M. Brenci, G. Nunzi Conti, S. Pelli, G.C. Righini, Index-profile reconstruction in ion-exchanged waveguides, Proc. MOC'04 (10th Microoptics Conference, Jena, 2004) paper L-23.

[21] C. Armellini, A. Chiasera, M. Ferrari, Y. Jestin, A. Chiappini, M. Mattarelli, M. Montagna, E. Moser, H. Portales, C. Tosello, L. Zampedri, V. Foglietti, A. Minotti, G. Nunzi Conti, S. Pelli, G.C. Righini, R.M. Almeida, S. Portal, A.B. Seddon, V.K. Tikhomirov, B. Gaillard-Allemand, V. Benoit, C. Arnaud, P. Féron, in: P. Biljanovic, K. Skala (Eds.), Proc. XXVII International Conference MIPRO 2004, MIPRO, Croatia, 2004, p. 15. 